\title{
DEVOTE FPISTELEN
}

(in Hs. n". $133 \mathrm{~F} 22$ der Koninklijke Bibliotheek to 's-Gravenhage),

MEDEGEDEELD DOOR

\section{A. BRINKERINK.}

I.

Dat indertijd de Windesheimers op het gebied van kloosterhervorming eene groote vermaardheid bebben bezeten en daardoor duizenden tot zegen zijn geworden, is van algemeene bekendheid. Met name het ten jare 1412 in het Generaal Kapittel van Windesheim opgenomen vrouwenconvent te Diepenveen bij Deventer ${ }^{1}$ ) heeft zich te dezen opzichte geenszins onbetuigd gelaten. Zoo lezen wij in het merkwaardige "Handschrift D", d.i. Van den doechden der vuriger ende stichtiger susteren van diepen reen ${ }^{2}$ ), gedurig van zusters, die elders, tot ver buiten de

1) Zie Thomas a Kempis, Chronicon canonicorvm regularivm Montis S. Agnetis, Antv. 1621 [achter het straks te noemen Chronicon $\mathrm{W}^{\mathrm{T}}$ indesemense (ed. Rosweyde) van J. Busch], p. 170, waar wij lezen : ${ }_{n}$ Anno Domini M. CCCC. duodecimo in generali capitulo domus sanctimonialium in Diepenuene, et domus sanctimonialium in Bronopia generali capitulo sunt incorporatae".

2) De tekst van dit handschrift - het tot dusverre verschenen Eerste Gedcelte van het geheele werk - is door mij uitgegeven en toegelicht in de Bibliotheek van Middelnederlandsche Letterkunde, A丹. 70, 72 (beide Gron. 1903), 73-74 (Gron. 1904). 
grenzen van het vaderland, begeerd worden om, gelijk het heet, nu eens in een klooster "een guede ordynancie te maken" (bl. 126d, 133a) en dan weder kloosterlingen te "informyeren" (bl. 129c) of onder ben "een guet fondament der geestelicheit" (bl. 181a) te leggen: in én woord, ow als Lervormsters op te treden. Verder, Johan Lindeborn noemt op p. 163 van zijne "Historia sive Notitia episcopatus Darentriensis" (Col. Agr. 1670) niet minder dan vijftien geestelijke huizen in Noord-Nederland, ZuidNederland en Duitschland, welke doör Diepenveenschen òf alleenlijk zijn verbeterd òf nieuw ingericht overeenkonstig den voor de Windesheimsche Congregatie geldenden Regel van St. Augustinus 1). Maar genoeg tot kenschetsing van den onmiskenbaren invloed, die, bepaaldelijk in de eerste helft der vijftiende eeuw, tot op de zware sterfte $\operatorname{van} 145{ }^{2}{ }^{2}$, toen de hoogste bloei van het convent

1) Deze is door Prof. W. L. de Vreese te Gent in Het Belfort van 1894 uitgegeven onder den titel: Sint Augustijns Regule in Dietsche met een fragment der "Bediedenesse".

2) Zie $H s . D$, bl. $81 b, 138 a$ volg.; vooral bl. $145 c-163 c$ ( $D$ ie suverliken droem.... vandergroter bruloft, die ten diepenveen wesen solde").

Bij de $\mathbf{2}$ ware sterfte van $\mathbf{1 4 5 2}$ hebben wij zeer waarschijnlijk te denken aan de bekende pestepidemie, die tegen het midden der vijftiende eeuw van uit het Zuiden - Saragossa, Barcelona en Milaan worden met name genoemd - over gansch Europa zich verbreid en eenige jaren achtereen gewoed heeft ( $n$ circumgyravit successive omnes terras durans per aliquot annos", zegt een geschiedschrijver). Deze ${ }_{n}$ bubonen- of builenpest", voorafgegaan als zij werd door kometen, overstroomingen en andere buitengewone natuurverschijnselen, heeft duizenden menschenlevens gekost. Verg. N. Webster, $A$ hrief history of epidemic and pestilential diseases, Vol. I (Lond. 1800), p. 231 : "In January 1449 was seen a comet. This year the plague raged in Italy, and in 1450 famine and plague. In Milan perished 60,000 people. This plague of 1450 is said to have arisen in Asia, and afterwards spread over Italy, Germany, France, and Spain, leaving alive scarcely a third of the human race".

Een paar jaren geleden heeft wijlen Dr. H. F. A. Peypers te Amsterdam in een schrij ren van 4 en van 9 Januari 1908 mij nog de navolgende inlichtingen verstrekt: ${ }_{n} \mathrm{O}_{\mathrm{p}}$ grond van de ofschoon rage ziekteverschijnselen, in Hs. D. t.a. p. genoemd, zal met de $z$ ware sterfte te Diepenveen in 1452 (er bezweken toen daar 19 of 20 zusters) blijkbaar de pust ziju beloeld en allerminst eene influemza-epidemie, gelijk men 


\section{4}

reeds achter den rug lag, is uitgegaan van Diepenveen, het modelklooster voor de nonnenwereld van die dagen 1), "het voorbeeld, de bloem, het sieraad en den roem van alle religieuzen die toen door goede tucht, stipte gehoorzaamheid, het afsterven van zich zelven en een hemelsch leven haren God wenschten te dienen", zooals ongeveer luidt het loffelijk getuigenis van den tot oordeelen bevoegden tijdgenoot Johan Busch, den beroemden kloosterinrichter en kloosterhervormer uit de vóór-reformatorische eeuw $\left.(1399-1479)^{2}\right)$.

Bij schrijven van 2 December 1419 verleent Bisschop Frederik van Blankenbeim officieel zijne toestemming om in de onmiddellijke nabijheid van de plek waar even buiten Utrecht's boofdstad de kapel Jeruzalem zich bevindt, een nonnenklooster te stichten, op voorwaarde, dat dit volkomen onderworpen zal zijn aan den prior en het Generaal Kapittel van Windeshein. Het is eene weduwe, Agatha Eernstes (Latijn: Agatha Ernesti) geheeten, die, na lang te voren het plan tot stichting van een convent ontworpen te hebben, thans aan de stichting zelve een werkzaam deel neemt, hierbij krachtigen steun ondervindende van zekeren Meester Bruno. Aan bewoonsters zal het niet behoeven te ontbreken. Degenen die zich komen aanmelden, onder wie verscheidenen zijn, met aardsche goederen rijk gezegend; doch in de eerste plaats de leden eener reeds bestaande Vereeniging van vrome vrouwen, met Agatha Eernstes als bestuurster, - zij vormen de bevolking van het op te richten klooster. Men begint te bouwen: wij laten in het midden, of zulks geschied is

aanvankelijk, bij oppervlakkige lezing van den tekst, zou meenen. Influenzin-epidemieen zijn ongetwijfeld in de Middeleeuwen voorgekomen, o. a. in de jaren 1310,1327 en 140.1, doch niet omstreeks het midden van de vijftiende eeuw, dat integendeel in de geschiedenis bekend stant als eene pestperiode over een groot deel van Europa".

1) Verg. W. Moll, Kerkgeschiedenis van Nederland vóir de Hervorming, DI. II, st. ii (Arnh. 1867), blz. 212.

2) Zie zijn Chronicon Windesemense (ed. II. Rosweyde, Antv. 1621, p. 191 ; ed. K. Grube, Halle, 1886, p. 362). 


\section{5}

terstond na het verkregen bisschoppelijk verlof van 2 December 1419 , waarop ik de aandacht vestigde, dan wel alreede in 1418 , het jaar, dat volgens het "Chronicon auctius Johannis de Beka" (verg. A. Matthaeus, "Veteris aevi Analecta", ed. 2da, Hag. Com. 1738, Tom. III, p. 371) gewoonlijk als het stichtingsjaar wordt aangenerkt. Hoe bet zij, zoo spoedig mogelijk worden, blijkbaar nog uit den boezem van de genoemde Vereeniging, vijf zusters eerst drie, vervolgens twee - gezonden naar Diepenveen, ten einde vooraf daar zoowel de levenswijze der inwonenden als den door deze kanunnikessen gevolgden orderegel van nabij to beschouwen, te bestudeeren, en naderhand beide in het eigen klooster volledig toe te passen. De uitgezondenen blijven eenigen tijd in het Overijselsche en stellen zich te Diepenveen van alles op de hoogte. Op haren terugtocht worden zij vergezeld van twee Diepenveensche zusters: de suppriorin Lijsebeth van Delft, aangezocht om, „doe dat cloester, iherusalem geheiten by utricht, begonnen waert, daer een guedo ordynancie te maken", en Belia van Dusseldorp, eene conversin. De eerste wordt, na in het nieuwe convent eene wijle als rectrix werkzaam te zijn geweest, in 1420 tot priorin aldaar gekozen; drie jaren later "op sante Angustijnus octave", d. i. den 4den September 1423, bezwijkt zij aan de tering. Belia van Dusseldorp gaat na zuster Lijsebeth's dood met groote blijdschap naar haar geliefd Diepenveen terug, waar zij $1444^{l}$ ) sterft.

Ziedaar in vluchtige omtrekken het roornaamste, dat

1) Dit sterfjaar is te vinden: $a$. bij A. Yatthaeus, Vita virginis nobilissimae Elisabethae van Heenvliet et quarundam aliarum in coenobio de Diepenveen (achter zijn Anonymi Chronicon ducum Brabantiae, Lugd. Bat. 1707), p. 229 [in de aldaar medegedeelde ${ }_{n}$ Lijst van Diepenveensche zusters"]; $b$. bij F. H. van Heussen en H. van Rijn, Oudheden en gestichten van het bisdom van Deventer, Leid. 1725, DI. II, blz. 181 (in dezelfde lijst, maar uit het Latijn vertaald); en c. in het "Necrologium der nonnen, conversinnen, enz. van het klooster te Diepenveen" in Hs. $\mathfrak{n}^{0} .23$ der Athenaeum-Bibliotheek te Deventer (zie [J. C. van Slee], Catalogus der handschriften berustende op de Athenaeum-Bibliotheek te Deventer, Dev. 1892, blz. 10). 
de bronnen ons verhalen aangaande de wording en vroeg. ste lutgevallen van het in 1424 bij de Congregatie van Windesheim ingelijfde, zeven jaren daarna afgebrande, maar weder opgebouwde vrouwenklooster, hetwelk in de geschiedenis bekend staat als "Domus Hierusalem" of "Domus Iherusalem", d.i. Jeruzalem bij, later binnen Utrecht. De bijzonderheden, door $\mathrm{mij}$ in herinnering gebracht, zijn ontleend: deels aan de opgave van data en fata, voorkomende blz. 209-212 van het Derde Deel van "Het klooster te Windesheim en zijn inyloed" (Utr. 1875-1880) door Prof. J. G. R. Acquoy; deels aan het "Chronicon Windesemense" (ed. H. Rosweyde, p. 195197; ed. K. Grube, p. 363 seq.) van J. Busch; deels, inzonderbeid wat de verbouding tot, de hervorming door en den invloed vau Diepenveen betreft, aan het boven geciteerde, alleszins betrouwbare "Handschrift $D$ " (zie aldaar bl. $55 c-d, 132 d-133 a, 158 d)$.

Het is het "Chronicon Windesemense", dat van de uitzending van Jeruzalemsche zusters naar Diepenveen melding maakt en dit doet met de volgende bewoordingen: "Ex ista sancta congregacione primum tres sorores, deinde duo misse sunt in Diepenvene, ut bonam earum regularis observancie formam oculata fide conspicerent, quam in omni forma proprio in monasterio postmodum servarent" (ed. Grube, p. 364). Er wordt aan toegevoegd, wat trouwens reeds is opgemerkt, dat de zusters bij haren terugkeer met zich krijgen als hervormster de zeer godsdienstige Lijjsebeth van Delft, door den schrijver echter "Elizabeth de Doesborch" genoemd, de aanstaande en eerste priorin , van Jeruzalem 1).

Voor de alzoo uit meergemelde Vereeniging van vrome vrouwen, voor de "ex ista sancta congregacione" afgevaardigde en mitsdien in eene haar onbekende omgeving verkeerende Jeruzalemsche zusters zijn de brieven be-

1) Doch verg. J. G. R. Acquoy, Het klooster te Winllesheim en zijn invloed, Dl. III (Utr. 1880), blz. 210, de aanteekening. 
stemd, die der Redactie van dit "Archief" ter publiceering worden aangeboden. Het zijn pennerruchten van zuiver stichtelijken inhoud, "Devote epistelen”, de benaming waarmede zij zich zelve komen aankondigen en die ook door mij als opschrift boven deze bladzijden is geplaatst.

Bedoelde epistelen, drie in getal, worden gevonden in een goed geconserveerd handschrift uit de vijftiende eeuw, dat, samengebonden in stevigen modernen band met een ouden druk van omstreeks 1506, een werkje vormt, hetwelk, waarschijnlijk in zijn geheel, eertijds heeft toebehoord aan de zusters van het Ursulinenklooster Jeruzalem te Venray. In 1897 werd dit werkje, watarvan geen tweede exemplaar schïnt te bestaan, op eene auctie te Bonn aangekocht door de Koninklïke Bibliotheek te 's-Gravenhage, waar het tegenwoordig als Hs. $\mathrm{n}^{0}$. $133 \mathrm{~F} 22$ berustende is.

Een gedeelte van het handschrift, bl. $88 r-93 v$, is onder den titel "Uit de kleinere ascetiscbe geschriften van Thomas a Kempis" door mij uitgegeren in "De Katholiek", Dl. CXXVIII (jaarg. 1905, II), blz. 276-290; daar kan men in de inleiding (zie vooral blz. 276-280) het unicum beschreven vinden, met opgave van de stukken, die er in zijn opgenomen ${ }^{1}$ ). Een ander gedeelte, bl. 82v$88 r$, inhoudende "Uitspraken $\nabla$ an "leismeysteren" " en "Exempelen aangaande hen", is mede door mij bewerkt en zal vermoedelijk nog in den loop van dit jaar, eveneens in "De Katholiek”, bet licht zien.

De "Derote epistelen" worden ons medegedeeld bl. $33 r-66 v$ van het handschrift, namelïk:

A. Bl. $33 r-47 r$, de eerste der epistelen, met het opschrift: Hier begynt een deroote epistel,

1) Zie nog aangaande het handschrift: Verslag over den toestand der' Koninklijke Bibliotheek in het jaar 1897, 's-Gravenh. 1898, blz. 41-42; ook mijne bijdrage "Deuoete epistelen", gericht aan zich te Diepenveen levindende zuster's uit het klooster Jeruzalem bij Utrecht [in het Archief voor de Geschiedenis van het Aartslisdom Utrecht, Dl. XXVII (Utr. 1901), blz. 300-302].

IV. 
ghescreven tot sommeghensusteren van iberusalem buten utrecht, die toediepenven ghesent waren o m.... De woorden "waren om", enz. zijn aan de rechterzijde der bladzijde van boven naar beneden geschreven; maar omdat het blad is afgesneden, kan hetgeen op "om" volgt niet meer ontcijferd worden. Uit de nog aanwezige letteroverblijfselen meen ik te moeten opmaken dat er gestaan heeft, evenals in het onderschrift van den tweeden epistel: "hem te proeven" (hs.: proeuen), of iets dergelijks.

B. Bl. $47 r-53 r$, de tweede der epistelen, met het opschrift: $\mathrm{H}$ i er bog h y t e e $n$ ander epistel. Aan het slot: Hie eyndet een devote [epistel], gheschreven tot someghenzusteren van iherusalem buten utrecht, die ghesent warentoe[die]penven om hem teproeven Inder orden.

C. Bl. $53 r-66 v$, de derde der epistelen, met het opschrift, in doorloopenden tekst onmiddellijk zich aansluitende aan de onder $B$ opgegeven slotwoorden: $\mathrm{H}$ i $\mathrm{er}$ beghynt een ander devoet $\theta$ pistel, gheschreven totten selven zusteren: woesi hem oefenen solden Inden waeldaeden ende inder passiën ons lieven beren Ihesu c risti. Deze epistel bestaat uit drie gedeelten, bl. $53 r-$ $57 v$, bl. $57 v-64 r$ en bl. $64 r-66 v$, waarvan de laatste twee afzonderlïke opschriften dragen 1$)$.

Alle opschriften - ook het onderschrift op bl. $53 r-$ zijn met rooden inkt geschreven, wat evenzeer het geval is met de beginletters van de eerste woorden der epistelen en der epistelgedeelten.

De taal is het Oostmiddelnederlandsch, hier on daar Duitsch gekleurd; een bewijs, naar het mij toeschijnt, dat,

1) Volgens het Verslag over den toestand der Bon. Bibl. in het jaar 1897, blz. 42, eindigt de derde der "Devote epistelen” bl. 64r. Dit is onjuist; verg. Arch. v. h. Aartsbisd. Utrecht, Dl. XXVII, blz. 301, de aanteekening. 
zoo niet de schrijver of schrijfster dan toch degene die de epistelen heeft gekopiëerd, af komstig is uit de streken, waar, hetzij in de oostelijke provinciën van Nederland hetzij vlak over de grenzen, het Saksisch dialect gesproken werd. Het verdient opmerking: dat van bl. $33 r$ tot $38 r$ (bovenaan) de meeste letters kleiner zän en enkele een ietwat ander karakter vertoonen dan die van hetgeen volgt; verder, dat daar niet het gewone paragraafteeken is aangebracht, maar een met rooden inkt aangestreept teeken, hetwelk veel overeenkomst heeft met de hoofdletter "E" en zó6 ook in de straks volgende uitgare zal worden weergegeven; en in de derde plaats, dat daar, in tegenstelling met bl. $38 \mathrm{r}$ (bovenaan) tot $66 v$, op zes uit-

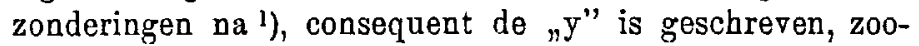
wel in tweeklanken als in open en gesloten lettergrepen ${ }^{2}$ ). De vraag rijst, of misschien twee personen de epistelen zullen bebben gekopiëerd. Mogelijk is het; zeker acht ik voor mij het niet, eerder onwaarschijnlijk.

De vóór ons liggende tekst wemelt van verschrijvingen en doorbalingen, van schromelijke willekeur terens ten aanzien van de spelling, een gewoon verschijnsel in de literatuur uit het laatst der Middeleeuwen. Bovendien zijn berbaaldelijk letters, niet zelden ${ }^{\mathrm{c}}$ " en ${ }^{\mathrm{r}}$,,herbaaldelijk woorden of woorddeelen weggelaten en weggevallen; eene enkele maal is door bijschrijving de noodige verbetering tot stand gekomen. Geeft derhalve het geheel den indruk van slordig, in haast te zijn afgeschreven, het is om die reden niet altijd even gemakkelijk geweest eene bedorven lezing te herstellen of zich uit te spreken over een rorm, afwijkende van de doorgaans gebezigde spelling.

De vermoedelijk niet bewaard gebleven oorspronkelijke epistelen - het is al gebleken, doch verkrïgt bị kennisneming van den inhoud zijne bevestiging - verplaatsen ons naar, dateeren uit de dagen, toen de Jeruzalemsche

1) Bl. $33 r-38 r$ (bovenaan) heeft de volgende niet met eene $n y$ " geschreven woorden: begynt (bl. 33r, Opschrift); hy (bl. 35v, in $n^{\text {als }}$ hy van u begheert"); symen, vertyen, menyngen, bynnen (alle bl. 37v).

2) Verg. beneden, blz. 322 . 
zusters geen kloosterlingen nog waren, maar voorloopig slechts het drukke gewoel en de ijdelheid der wereld hadden vaarwel gezegd (zie bl. $33 r$ volg.) on deel uitmaakten van de onder Agatha's leiding staande Vereeniging. De naam van schrijver of schrijfster is niet bekend. Hebben wij hem, hebben wij haar in het GelderschOverïselsche te zoeken, of vooraan in Duitschland? Bij gebrek aan aanwijzingen op dit punt is het moeilijk zich met zekerbeid uit te laten. Het vermoeden ligt voor de hand te denken aan eene zuster uit Jeruzalem, behoefte als zij heeft gevoeld om den in rreemden kring, ver van huis zich ophoudenden medezusters van voorlichting te dienen, een ernstig, uit de ziel gegrepen woord bij wijze van leiddraad onder de dagelijksche overdenkingen en zelfbeproevingen haar op het hart to binden. Degene die de epistelen heeft gesteld, meent op den naam van "philosophe" geen aanspraak te moeten maken (verg. bl. 53v). Wel is het iemand geweest van goeden wil en in hooge mate godsdienstig, deroot en tegelijkertijd mystiek, maar van geringe letterkundige ontwikkeling; een die de woorden allesbehalve "suetelick ende treckelick" vermocht te schrijven, vanwege zekere aangeboren "plom[p]heit ende rudicheit" (bl. 54r); een die daarom, in denzelfden rolzin, den lezeressen in overweging geeft: "Ghi moeget selve die woerde in merre mynliecheit veranderen ende formieren, als $u$ die geest gades ende verlichte reden wael wisen ende leren sal".

Het valt niet te ontkennen dat aan den eisch der oorspronkelijkheid meermalen is te kort gedaan.

Wat den eersten brief betreft, er komen gedeelten in voor, die somtijds woordelijk zijn overgenomen uit Hendrik Mande's "Liber de tribus statibus hominis conversi", door den Hoogleeraar W. Moll onder den titel „Hier beghint een boecskijn van drien Staten eens bekierden mensche", enz. uitgegeven in zijn "Johannes Brugman en het godsdienstig leven onzer vaderen in de vijftiende eeuw" (Amst. 1854), Dl. I, blz. 263-292. Meer in het bijzonder zijn bet de laatste twee gedeelten geweest van bet 
werkje van Mande, die hunne goede diensten hebben bewezen en die door Moll worden medegedeeld t.a.p. blz. 277-282 en blz. 282-292, met de opschriften: $\nabla$ an enen geestliken of ynnighen leven, wat $\theta e n$ gheestlic leren is ende wairindattet gheleghen is ende wat hem $h \ddot{j} n d e r t$ en $\nabla a n$ enen scouwenden leven, ende wat $\theta e n$ scouwende leven is ende wairin dattet ghelegen is, ende van sommighen punten die daerin bijnderen $\left.{ }^{1}\right)$. Ik roeg er aan toe dat met bl. $42 v$ ( "Hier om”, enz.) tot $45 r$ ( inder waerheit") uit dezen eersten brief nog kan vergeleken worden F. H. G. van Iterson, „Stemmen uit den Voortijd", Leid. 1857, blz. 49-50.

De tweede brief staat onder den invloed van Jan van Ruusbroec: er worden passages in gevonden, niet altijd woordelijk, toch in elk geval zakelijk ontleend aan het "De vera Contemplatione opus praeclarum", zooals de titel luidt in de Latijnsche vertaling van L. Surius, "Dat Boec vanden twaelf Beghinen", zooals het werk gewoonlijk en in het Dietsch genoemd wordt. Het is Caput L.X van dit werk ${ }_{n} \mathrm{D}$ e Castitatis consilio et $\nabla$ ot 0 , et quemadmodum castitatem tueri debea n t homines"), vooral het slot, dat hier tot voorbeeld heeft gediend; in Middelnederlandschen tekst staat het Caput afgedrult blz. 164-176 van het $\nabla$ ijfde Deel (Gent, 1863) der „Werken van Jan van Ruusbroec”, uitgegeven door J. David in de "Werken van de Haetschappy der Vlaemsche Bibliophilen".

Alles in aanmerking genomen, is de inhoud der "Devote epistelen" niet zonder belangrijkheid. Zij behelzen min of meer uitgewerkte levenswoorden voor de zusters aan wie zij gericht zijn: raadgevingen in het algemeen

1) Verg. Acquoy, a. w., DI. I (Utr. 1875), blz. 268, aaut. 1. - Zie over het aangehaalde werkje van Mande in zijn geheel G. Visser, Hendrik Manle. Bijdrage tot de kennis der Noord-Nederlandsche mystiek, 's-Gravenh. 1899, blz. 45-47. 
om te allen tijde den Christus na te volgen; voorschriften in menigte om te Diepenveen de reinheid ran hart en wandel onafgebroken to bewaren; wenken eindelijk, hoe zij daar zich hebben te oefenen in de bepeinzing van de woldaden en het lijden des Heeren, welke gezindheden zij moeten koesteren onder de mis, hoe zij zich dienen te gedragen in Gods tegenwoordigheid onder het gebed. Eenen "Spiegel" gelijk ${ }^{1}$ ), worden den Jeruzalemschen voorgebouden plichten en deugden in bonte verscheidenheid, altegader "goede punten", bij de Middeleeuwsche devoten uitermate geliefd en veelvuldig in zwang ${ }^{2}$ ).

Ik mag deze inleiding niet besluiten, zonder rekenschap te hebben gegeren van de wijze, waarop de "Derote epistelen" zijn bewerkt geworden. In zeven opmerkingen worde samengevat wat hierover valt mede te deelen.

Ten eөrste. De tekst is nauwkeurig naar het handschrift afgedrukt en volgens de methode, die door mij werd toegepast o. a. bij de uitgave "Goede punten uit de collatiën ran Claus van Euskerken" in den vorigen jaargang van dit "Archief" [Nieuwe Serie, Dl. III ('s-Gravenb. 1905), blz. 225-264, 352-395].

Ten tweede. Zonder uitzondering, van het begin tot het einde, heb ik eene "y" laten drukken: niet alleen bl. $33 r-38 r$ (bovenaan), waar, gelijk wij gezien hebben, zulks de bijna uitsluitend gebruikte spelling is en deze eenroudig behoefde overgenomen te worden; maar ook bl. $38 r$ (bovenaan)-66v, waar gevonden wordt nu eens ",", dan weder en meestal "ij" (zonder puntjes of verticale streepjes er boren). Het dien verstande ben ik echter te werk gegaan, dat in dit gedeelte, dus na bl. 38r (bovenaan), ieder in de uitgave van een sterretje roorzien woord aan-

1) Verg. Acquoy, a. w., Dl. I, blz. 160, 256.

2) Zie Acquoy, a. w., Dl. I, blz. 163 volg., 232, 242, 276, 279, 286; DI. II (Utr. 1876), blz. $301-303$. Verder raadplege men W. G. A. J. Röring, Thomas a Kempis, zijne voorgangers en zijne tijdgenooten, Utr. 1902, blz. 161 volg. 
wijst, hoe dat woord in het handschrift duidelijk het y-teeken heeft.

Ten derde. Aan het begin van een volzin is, dikwijls in afwijking van den tekst, steeds eene hoofdletter gebruikt.

Ten vierde. Waar het behoorde te geschieden, zijn "u" en "w" in ${ }^{\mathrm{v}}$ ", de " $\mathrm{\nabla}$ " in eene "w" veranderd; van de oplossing der "w" in " $\nabla u$ " is in de "Aanteekeningen" melding gemaakt.

Ten vijfde. Wat tusschen vierkante haakjes geplaatstis, staat niet in den telsst en dient in den regel om dezen te verbeteren, maar nu en dan ook om hem in overeenstemming te brengen met eene meest voorkomende spelling.

Ten zesde. Aan den voet der bladzijden zal men vinden enkele woord- en zinsverklaringen. De eigenlïk gezegde "Aanteekeningen", waaronder vrij uitvoerige en vaak van taalkundigen aard, bebben in den vorm van Bijlagen eene plats gekregen achter ieder van de drie epistelen.

Ten zevende. De interpunctie, of beter de schier geheele afwezigheid van interpunctie, is vervangen door die van onzen tijd.

Mij rest nog een woord van hartelijken dank to betuigen aan de Heeren Prof. J. Verdam te Leiden en Dr. C. G. N. de Vooys te Assen roor de inlichtingen, die ik bij de bewerking van mijne uitgave van hen heb mogen ontrangen: menige tekstverbetering is er het gevolg van geworden, menige duistere volzin is er door tot klaarheid gebracht.

B ovenkarspel, Juli 1906. 
DE EERSTE DER „DEVOTE EPISTELEN”.

(Bl. $33 r-47 r$.)

33 Hier begynt een devoete epistel, ghescreven tot sommeghen susteren van iherusalem buten utrecht, die toe diepenven ghesent waren om [hem te proeven].

0 Nse suete ende mynlike here ihesus cristus ${ }^{1}$ ), die een brudegom is der mynnender zielen, die roept ende vermaent die mynnende zielen altoes van bynnen ende secht: ${ }_{n} \mathrm{O}$ doechteren van iherusalem, gaet wt ende siet den coninck salomon in synre cronen, daer hem syn moeder mede gecroent hevet inden dage synre boechtit ende inden daghe der blyscap syns herten" 2). 0 dochteren ende susteren van iherusalem! want ghy dye stem uwes gheminden brudegoms ens dels ghehoert hebt, alsoe dat ghy overmids der hulpen ${ }^{3}$ ) [gades of gods] wt der menichroldyche[i]t $\left.{ }^{a}\right)^{4}$ ) ende yclelheit der werlt wt ghegaen syt, op dat ghy uwen ghemynden ghenaken ende vinden moecht; ende noch voert, overmids 5) ghehoersamheit ende ver-

33. manen uwes brudegoms wt iherusalem in (/ diepenveen ${ }^{6}$ ) ghecomen sit, op dat ghy uwen minlicken brudegom den waerachtighen salomon syen ende scouwen moeget ende hem hoeren spreken in sinen heilighen leden Soe ist merkelicken noet ende nutte dat ghy den ropen uwes gheminden voerichlicher ver-

- volghet mitten werken Alsoe dat ghy nyet te verghefs wt gheghaen en sit ende ghecomen in dye heilighe stat ende vergaderinghen der heiligher leden uwes brudegoms ons minlicken heren ihesus cristus. Op dat ghy dan dyt te rechte volbrenghen ende voldoen moeghet, soe is u sonderlinge noet Dat ghy, gelick als ghy gheropen syt mitten licham wter manichvoldicheit ende idelheit der werlt [ende 7$)]$ overmids den ropen uwes gheminden brudegoms hem nae ghevolghet sit Dat ghy oeck mit uwen herten ende begherten $u$ sceidet van allen creatueren, 34r dinghen ende oersaken, // dye u hynderlick mochten ${ }^{8}$ ) wesen in uwen gueden opsette.

a) Menichvoldycheit (= menichvoudicheit; term der devoten), drukte en gewoel der wereld, beslommering. Het togenovergestelde is "enicheit" (eenzaamheid, het zich afzonderen om zijne gedachten op God te kunnen richten). Verg. Moll, Joh. Brugman, Dl. II, blz. 422, 420 volg. 
E Hier om doet op die oghen uwes herten ende siet aen mit minlicker begherten den waerachtighen salomon ende vredsamen - dat is, uwen sueten ende mynliken brudegom onsen mynliken heren ihesum cristum -: hoe dat hy van onsprekelicker minnen, die hy tot $\mathfrak{u}$ ende tot allen minnende sielen ghehadt hevet ende noch hevet, aen ghenomen heft onse minslicker natuer vander heiligher ghebenedider maghet maria 9) synre moeder sonder enighe smette der sunden, die hem overmits den heilighen ghest in oeren magedeliken licham ontfanghen heft ende hem mit onser mynsceliker natueren ghecroent, op dat hy, die een scepper ende heer is hemels ende eerden ende al datter binnen is, een brudegom ende een broeder mochte werden der minnender sielen ende die overmids synre heiligher passiën ende // menigherhande teikenen der minnen 34. tot heem trecken mochte ende weder van oer ghemint werden.

E Hier om, o dochteren van iherusalem, gaet wt ende volghet synre minnen, die spreket vander minnender sielen ende seghet: „Ic sal se leiden in die enicheit, ende daer sal ic spreken tot orre herten" ${ }^{10}$ ). Yst dan dat ghy uwen gheminden volghen wilt, soe moeti u der manichroldicheit ontbreken ${ }^{a}$ ) ende gaen in die enicheit - dat is, tot uwer herten -, als u gheminden spreket ende seget: "Ghy die overghetreden sit" dat is, in sunden ende inclen onrechten weghe -, "keert weder ter herten" "). Daer suldi hoeren die suete ende die mynnelicke stem uwes gheminden, daer hy tot u spreket ende seghet: "hoer, dochter, ende sie, ende neighe din ohren ${ }^{19}$ ), ende verghet [din of dyn] rolck ende dat hủus dyns vaders" 13). Ende ist dattu dit duyst, soe sal die heer dine scoenheit begheren; want hi is din heer ${ }^{14}$ ) ende din got.

E Och mynlicke siele, sie ende merke wie hy is, die di tot $35 r$ eenre bruut vercoren heft: dat hy ghein ghemeyn redelic creatuer en is, mer din heer ende dyn got. Och, et is mer wonder ende mer dan wonder dat die ninnencle siele in oer selven bliven mach ende dat si nyet te mael en verandert van oer selven ende smeltet ende vloiet in oeren gheminden Als si hoert ${ }^{15}$ ), hoe groet, hoe mechtich, hoe edel, hoe scoen hy is, die oer overmids synre onsprekelicker guetheit ende ewigher mynnen tot enre bruit vercoren hevet.

E Hier om, 0 dochteren van iherusalem ${ }^{16}$ ), gaet wt, laet

a) „Hem ontbreken" (net den 3ilun naimv.), zich ontrckken aan, ontvluchten. 
eighen wille, eighen gutetduncken, stervet der natueren ende alre eighentheit ${ }^{a}$ ) ende volghet uwen brudegom, daer af ghescreven stet dat hy hem verblide als een rủese ${ }^{b}$ ), op dat hy lopen mochte den wech ${ }^{17}$ ) synre passiën ende $u$ alsoe tot hem 35. trecken // mochte ende mit hem verenighen; want, als hy spreket, soe is syn welden te wesen mitten kinderen der menschen ${ }^{18}$ ). Ist dan dat ghy hem truwe bewisen wilt ende hem volghen, als hy van u begheert, soe suldy mit vueriger ende minliker begheerten uwe hande slaen anden cruce sonder omsyen; want soe wie sin hant slaet aen die ploech ende weder om siet, die en is niet werdich des ewighen tevens ${ }^{19}$ ) Mer ghy sult mit vuerigher berten seggen: "Ick vermach al dynck inden ghenen die my sterket" ${ }^{20}$ ).

E Ende al yst dat die (luvel vreischet ${ }^{c}$ ) als een lewe Al ist dattet vleische mûrmerert Al ist [dat] die natuer claghet, gaet vrielick doer ende en achtes niet; want ghi hebt enen sterken hulper, die u niet inden eynde laten en sal ist dat ghi hem truwe sit Al ist dat hy sine gheminde sommels ${ }^{d}$ ) ene corte

36r tyt laet, op dat hy oer stantachticheit proeven // wyl in synre mynnen Endle op dat ${ }^{21}$ ) sy oec leren tot hem te vlien daer hem alle guet aff koemt Ende dat si oeck oers selffs krancheit leren kennen, dat si van hem selven niet en vermoeghen.

E Hier om, o dochteren van iherusalem, suldi merken ende sien ůwen brudegom in sinen leden - dat is, inden susteren daer ghy mede om gaet - ende uwen brudegom daer in eren, want hi alle doechden waerachtelicke werket in sinen heilighen leden, als ick hape dat si sonder twivel sin. Ende ghi sult die doghet in enen ieghelicken ${ }^{22}$ ) minnen ende die voer setten: soe moechdi der delachtich werden; ende pint a die doecht nae te volghen na uwer macht: ghi sult a selven tot alre ghehorsambeit ende ghelatenheit gheven nae den wille ons lieven

$36^{\circ}$ heren. Ghi sult onderdanich wesen gade, // uwen oversten ende alle den ghenen daer ghi bi ${ }^{23}$ ) sit, om uwes gheminde[n] wil, in allen dinghen die tot sinre eeren dienen moghen, op dat ghi

a) Eighentheit (= eigenheit; term der devoten), eigenliefde, zelfzucht. Verg. Moll, Joh. Brugman, Dl. II, blz. 421.

b) Rưese (= rese), held.

c) "Vreischen, vreiscen" (= vreeschen, vreescen), opsporen; eig. vragen, vernemen, onderzoeken. Verg. E. Verwijs en J. Verdam, Middelnederlandsch Woordenboek op g e $\mathrm{v}$ re escen.

d) Sommels, somtijds, nu en dan. 
uwen gheminden volghen moget, die seghet: „Ic en bin niet ghecomen dat ic minen wil doen sal" - dat is te verstaen

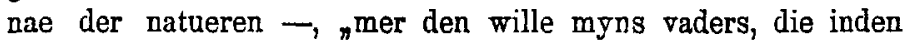
hemel is" 24). Ende hier om, ist dat ghi waerachtelicke dochteren ende susteren wilt wesen vanden hemelschen iherusaIem ${ }^{25}$ ) Soe moeti volghen uwen koninck ende gheminde brudegom, die seghet: "Die niet en laet vader ende moeder, suster ende broeder ende al dat hi besit ${ }^{96}$ ), ende oec hem selven, die en is niet werdich te wesen myn descipel" 27). Voert, ist dat ghi den lam volget - dat is, uwen gemynde volgen wylt waer hy gaet -, soe moetti u na // uwer macht hem in doechden 37r pinen te geliken van buten ende van bynnen.

E Ende hoe dat ghy meer waerachtiger doechden hebt ${ }^{28}$ ), hoe gy hem gelicker sit. Mer ist dat ghy allen ${ }^{29}$ ) staet op die dingen van buten, als lesen, singen, vasten, waken ende ander guede werken van buten ende dat ghi nyet en merket dat waer om noch dat einde alle deser dingen Soe suldi recht wesen als een gemaelde belde of gemaeld heiligen, daer gheen leven in en ys. Hyer om, ist dat ghi werden wylt gheestelike menschen, als uwen staet dat ${ }^{30}$ ) ghi aen nemen wylt toe behoert, ennde ${ }^{31}$ ) a gheren wylt tot ynighen leven Soe moetti uwes selves nauwe waernemen van by[n]nen wat in u gaet of wat wt $u$ gaet in woerden ende // in ghedachten. Ghi sult $u$ 37o pynen dat ghi u selven leert bekennen in uwen gront ende nauwe merken. Ghi sult u pynen te sterven alre behegelicheit uwes selves ende genochlicheit uwer synnen. Ghi sult u pynnen gade alleen mit herten te mynnen Ende al creatueren om got encle in got. Ghi sult uwes selves wt gaen ende verloe[c]henen off vertyen ${ }^{a}$ ) onder den lefsten ${ }^{32}$ ) wil gades in al uwen werken Ende ghi en sult $u$ selven nietes nyet ${ }^{b}$ ) toe schriven dan uwe gebreken; ende daer om suldi gade altoes hebben in uwer menyngen ende hem al guet toe schrieven. Ghi sult u selven halden suver ende ledich van bynnen: dat is, dat ghi u hueden sult na uwer // macht van quaeder begerten, van quaeden ver- 38r moeden ende van anderen menschen te ordelen.

a Oec suldi a pynnen* te wanderen in enycheit*33) uwes

a) Vertyen (= vertiën), afstand doen van, verloochenem. - "Vertiën" (nl. hein selven, eigen wille) is een term der devoten. Verg. Moll, Joh. Brugman, DI. II, blz. 424.

b) Nietes nyet (= niets niet), volstrekt niets, in het geheel niets. Nog komt de uitdrukking voor bl, 42". 
herten ende u selven geven tot ynnigen* ende devoten begerten; want die trecken onsen lieven heren totter mynnender ende oetmoediger sielen Als david die prophete seget: "Die begerten der armen" - dat is, der oetmoediger - "hevet die here gehoert ${ }^{34}$ ), ende die bereidinge oerre herten hebben din oeren" - dat is, des heren - "gehoert" ${ }^{35}$ ). Ghi sult u pynen mit mynnen te neygen* tot uwen gemynden; want sunte Augustinus ${ }^{36}$ ) seget dat gheen dinc en is dat onsen mynlicken heren lichteliker tot ons treckt dan oetmoedighe ende mynlicke 38v ney-//ghinge* ende begheerte der sielen tot hem. Ende hier om suldi $u$ pynen te swigen ende alleen te wesen; alsoe roele als ghi moeget, behoelden ${ }^{37}$ ) der mynnen; want daer steet gheschreven: "In swigen ende in hapen ${ }^{38}$ ) sal u stercheit wesen" ${ }^{9}$ ) Ende op een ander stat: "Het is guet dat een mensche sitte" ${ }^{40}$ ) - - dat is, dat hi hem veroetmoedige ende swige - Dat is, van allen onnutten ende ydelen* woerden, van idelen gedachten ende fantasiën boven hem selven - Dat is, dat hi alle tytlike en vergenckelicke dingen ende al datmen dincken ende ymagineren * mach lichamlic ende geestelic achter rugge setten [sal ${ }^{2}$ )] - ende clim, alsoe roel als hem moe[ge]lic is, in onbekentheit ende 39 r dusterheit, daer hi gade in on weten- $/\left(\left[\text { heit] }{ }^{a}\right)^{43}\right.$ ) schouwen mach. Ende dan mach hi hoeren wat die here in hem spreket, als die prophete seget: "want hi spreket vrede in synen* voelke ende tot die hem ter herten keren" ${ }^{44}$ ). Voert suldi waernemen der gottelicker manyngen * ende der bewegingen des heiligen gestes ende synne gracie ende gaven niet ydelic * ontfangen, mer u daer mede pinen te werken Soe moechdi hebbelic ende bequaem werden meer graciën te ontfangen. Oec suldi schuwen ledicheit van buten; mer wanneer ghi schint van buten ledich te wesen, soe suldi $u$ pynen van binnen te arbeiden ende $u$ te verenigen mit uwen gemynden mit vuerigen ${ }^{45}$ ) ende begeerlicken gebeden Ende $\mathrm{u}$ herte pinen tot hem te heffen. Ghi sult 390 oec schouwen te groete onle-//de; mer wanneer dat ghi overmits gehoersamheit off nutticheit onlede hebben moet Soe en suldi ll te mael daer niet ${ }^{46}$ ) op storten, mer ghi sult inder onleden van buten $u$ altoes pinen na uwer macht satiche[i]t

a) Onwetenheit (term der devoten), een visionaire toestand, waarin men, van het aardsche niets wetende of gevoelende, alleen vatbaar is voor indrukken van het goddelijke en hemelsche. Zie Van Iterson, Stemmen uit den Voortijl, blz. 175. 
des herten te hebben ende schouwen alle onmanierlike ${ }^{47}$ ) haesticheit daer ghi moeget; want si hindert oec ducwil inden werken, dat si niet volcomelick ghedaen en werden nae oeren toebehoeren. Alle dingen suldi doen mit onderscheide ende in enre gherechter ghelatenheit uwes selves, op dat u eygen* wil in uwen werken niet ghevonden en werde ${ }^{48}$ ) Mer ghi sult altoes seggen mitteu monde ende meynen ${ }^{*}$ mitter herten: "Heer ${ }^{49}$ ), uwen wil gheschie ende niet die myn!" " 0 )

(a Voert sul-//di scouwen al ydelheit*51) in uwen seden, 40 in woerden ende in gelaet Ende sult vlien alle mennichrofl]dicheit ende pynen $u$ mit uwen gemynden in enicheit uwes herten te rusten.

a Altoes na uwer macht suldi u pinen te gebruken gotlike tegenwordicheit. Ende wat ghi siet van creatueren ende van den dingen die got geschapen heft, dat suldi altoes trecken tot uwen besten ende laten $u$ duncken dat si $u$ toe spreken ende seggen: "laevet den heren, die ons gemact heret tot uwer behoeff, ende dancket hem; want wi en hebben ons selven niet gemact": hoer wesen dat is hoer stem, als sunte Augustinus ${ }^{52}$ ) secht. Ende alsoe moechdi leren gode schouwen in allen creatueren. In allen uwen wercken ende oefeningen van buten ende van bynnen suldi altoes meer meynnen * ende soeken die eer ende dat // loff gades dan uwes selves bate off 40. nutticheit: soe suldi guede vrucht voert brengen. Ghi sult mynnen ende pinen $u$ te crigen reinicheit des herten ende vrede der conciencen, ghestadicheit in sinnen ende ghesaticheit van binnen ende enicheit van geste: pynt $u$ [te] hebben een ghemene mynne tot allen menschen om got ende in gade Ende ghi sult alle creatueren aen sien op oer edelste ende merken oer edelheit ende waer om ${ }^{53}$ ). Ende aldus suldi in allen dingen u beste soeken ende uwen gheestelicken orber doen.

a Ghi en sult niemant ordelen dan u selven; want onse heer seget: "Ende [en] wilt ordelen naden anschyne van buten" ${ }^{54}$ ), want daer woert menich in bedra-//gen. Daer om $41 r$ suldi alle dinck op hem selven laten staen ende laeten den genen ordelen die die herten ende die nyeren ${ }^{*}$ ondersueket ${ }^{55}$ ), want hem hoert al ordel toe. Ghi [sult] a pinen ledich te bolden van dat $\mathrm{u}$ niet en hoert ende u luttel onderwinden van den ${ }^{56}$ ) dingen die $u$ niet beroelen syn: soe moechdi vrede holden in u selven ende anderen menschen daer [ghi ${ }^{~} 7$ )] bi syt 38 ). 
a Oec en suldi in genen dingen vrede sueken noch genochte dan in gade ende dat gade toe behoert off dat $u$ tot gade leiden mach. Gheen dinck en sal u ontfreden a) noch ontsetten $\left.{ }^{b}\right)^{59}$ ) dan sonde ende verlies van geestelicken goede. Oec en sal u geen dinc moegen verbliden dan doeget. Ghi en sult [niemant $\left.{ }^{60}\right)$ ] 41. ontsien dan gade: dat is soe te verstaen, dat // ghi niemant alsoe ontsien en sult, dat ghi om enichs menschen wil off ontsich doen sult tegen uwen gemynden heren off tegen synen gebaden. Ghi en sult niemant begeren te behagen dan uwen ghemynden off om sinen wille, dat hi in u geloevet ende ghedanket werde.

(I Ghi en sult gheen verikiesen hebben inden dingen noch eigenschap ${ }^{61}$ ), mer laten onsen lieven heren ghewerden ende mit $\mathrm{u}$ doen dat hi wil: soe suldi altoes winnen ende niet verliesen. In allen menschen suldi die doeget $m y[n] n e n$ ende die hem leven ende helpen sterken mit rade ende mit dade ende mit al dat ghi vermoeget Soe suldi deelachtich werden alder gueder werken; want die mynne en mach niet veriliesen ${ }^{62}$ ).

a Willige armoede ende afgescheidenheit suldi mynnen ende 42r die // in allen dingen begeren nae uwer cran[c]heit ende macht. Alle dingen die op $\mathrm{u}$ coemen, et si vanden menschen, vander verhenkenisse gades off anders van buten off binnen in wat manieren dat se got gestredet, die suldi al mit oetmoediger herten ontfangen vander hant uwes geminden als een groete ende sunderlinge gave ende hem daer [ $\operatorname{ran}$ of af] dancken ende laeven.

a Ghi sult u selven ducwile ende altoes offeren ${ }^{63}$ ) uwen minliken bruedegum mit al dat ghi vermoeget, ende alle creatueren. Oec suldi a pinen myt begerten uwen gemynden aen te cleven - dat is, overmits mynnen synre guetheit nae ${ }^{6 t}$ ) te volgen - Ende ghi sult u pinen mit crachten op gherichtet te staen van binnen tot enicheit. Altoes suldi oec pinen in $u$ 42. selven onge- $/\left(\right.$ deilt $^{c}$ ) ende onverbelt ${ }^{d}$ ) van herten te wesen Soe

a) "Enen ontfreden" ( $=$ ontvreden) is een term der devoten, beteekenende aan iemand zijn orede of rust benemen, hem van zijn vrede of gemoedsrust berooven. Verg. Moll, Joh. Brugman, Dl. II, blz. 423.

b) "Enen ontsetten", iemand in de war brengen, hem verstoren, hem verbijsteren.

c) Ongedeilt (= ongedeelt; term der devoten), uitsluitend op het goddelijke en hemelsche gericht, niet door het aardsche afgetrokken. Verg. Moll, Joh. Brugman, Dl. II, blz. 422.

d) Onverbelt (= onverbeeldet; term der devoten), niet met zinnelijke 
moechdi u altoes rryelick op heffen ende tot uwen gheminden keren.

a Ghi sult u pinen simpel ende eenroldich te wesen ran binnen in a selven ${ }^{65}$ ) ende schinen van buten dat ghi binnen syt ende van buten toent. Die werlt ende oer werken sal $u$ een cruce wesen ende ghi der werlt, alsoe dat ghi niets niet ghelikes mit der werlt hebben en sult.

a Gheen dinc en sal in $\mathfrak{u}$ stat hebben dan got Noch gheen mensche en sal in a eigenschap hebben dan om got ende alsoe veer alst gade erlic is. Ende aldus suldi u altoes halden in eenre gotliker ghelicheit na den belde ons minlicken heren.

a Hier om, o susteren ende doechteren van iherusalem, suldi altoes aensien ende bekennen sonder onderlaet a) // die guetheit $43^{r}$ ende die werdicheit ende die volcoemenheit uwes geminden brudegums Ende merken dan weder die clen[i]cheit ${ }^{66}$ ) ende gebreclicheit ende nodurfticheit uwes selves, die edelheit uwer sielen ende vroude des ewigen leve[n]s. Ghi sult merken vruchberheit der doeget, ende altoes suldi staen op een netmoedich vertiën ende vernieten off versmaden nwes selves van binnen, ende sult $\mathfrak{a}$ laten mit rechter herten onder garle ende onder allen creatueren ende dencken altoes dat gi die mynste syt onder allen menschen; want ghi en sult niet meer van u selven holden dan ghi [ $\left.\left.\operatorname{van}^{67}\right)\right]$ u selven hebt: dat is, niet dan sonde. Ghi sult altoes beginnen ${ }^{68}$ ) een nië leven ende u selven oefenen in nyer waerheit te bekennen. Ghi sult u pinen dat ghi hebt lattel woerde ende voel // levens. Al u gebreken suldi groet $43 \mathrm{v}$ achten ende $u$ ontbliven ${ }^{b}$ ), mer niet clenmoedich wesen noch becoemert daer om werden Mer ghi sult altoes op setten $u$ te beteren mit vresammer herten ${ }^{69}$ ) ende hapen op die guetheit gades, dat hi u helpen sal. Alle doeget ende al dat ewich is suldi groet rekennen ende wegen, ende ghi sult die werlt, al dat vergenckelic is, clein wegen ende niet achten. Ghi sult begeren ongeacht te wesen van allen menschen, alsoe voel alst in $u$ is, om die eer gacles. Ghi sult $u$ altoes holden dat ghi

beelden en voorstellingen vervuld, ontvankelijk voor indrukken van het goddelijke en hemelsche. Verg. Moll, Joh. Brugman, Dl. II, blz. 422. - Zie bl. $51 r$ : verbelden.

a) Sonder onderlaet (ook bl. 62r), zonder ophouden, onafgehroken, aanhoudend, steeds.

b) Ontbliven (de onbep. wijs als zelfst. naamw. gebruikt), gebrek, tekortkomingen. 
gades nummer en gemissen in uwer sielen ende dat alle menschen van u ghebetert werden, die u sien off hoeren spreken 70 ). //

44r Ghi sult $u$ alsoe hebben in uwen seden ende woerden, dat men an a merken mach dat $u$ rick van deser werlt niet en is ${ }^{71}$ ). Al doechden suldi u pynen to wercken op oer volcoemeste ${ }^{22}$ ) ende wesen dien dingen genoch die ghi ve[r]staet ${ }^{73}$ ), tot dat ghi op een beter ${ }^{74}$ ) ghewyst werdt. Daer na suldi u pynen dat ghi gheen dinc en duet inder tyt, dat u rouwen mach naeder tyt.

a Hier om suldi u pynen in langen langen 75 ) lyden te hebben een staedige verduldicheit ende in mennichvoldicheit een ver$44^{\circ}$ sament ${ }^{76}$ ) gemoede. Ghi en sult niet eygens* $/ /$ hebben inder tyt noh ${ }^{77}$ ) $u$ selven soeken in ghenen dingen, lyfflic noch geestelic. Oec suldi u mit niet mynres laeten ghenoegen dan mit gaede, ende ghi en sult oec niet meer begeren. Ghi en sult in u niet laeten coemen dan ${ }^{78}$ ) got: van allen dingen ende van allen creatueren, alsoe voel als moegelic is, suldi $u$ aff scheiden mitter herten, ende sult u pinen ledich te wesen van allen inghetoeghenen ${ }^{a}$ ) beelden ende uwe ghemoede vryen van allen toevalle. Ghi sult altoes pinen te leven, off ghi morgen off te handes ste[r]ven solt Ende ghi sult nauwe merken wat 45r ghi syt ende waer ghi syt ende ${ }^{79}$ ) // wat ghi ghewest hebt, waer ghi hennen sult of moet, wat $u$ leven is of oefeninge, wat in haepe is ende u onderstant, ende blieven ghestaedich inder doeget ende volstandich inder waerheit.

a 0 dochteren van iherusalem! dit is daer ghi van uwen gheminden toe gheroepen syt Dat ghi die ghebreken ende die ondoecht wt doen sult ende mit desen clederen [u] cleden, op dat ${ }^{80}$ ) ghi uwen gheminden ghelic moeget werden ende u mit hem verenigen. Ende hier in is een gestelic leven ghelegen; ende daer om moechdi hier in merken, hoe nae of woe veer dat ghi syt enen rechten geestelicken leven. Ende hier nae

45. suldi altoes, alsoe // lang als gi left, [u pinen $\left.{ }^{81}\right)$ ] dat gi dit vercrigen ${ }^{82}$ ) moeget; ende ist dat ghi volstandich blivet in

a) ${ }_{\pi}$ Inghetoeghen" ( $=$ ingetogen; term der devoten), er (ij gehanld, van lutiten af gehaald. Het woord komt nog eenmal in het hs. voor, nl. bl. 87" (verg. Stemm., blz. 33), waar wij vinden in letterlijken afdruk: "Dat ander is dat ic ledich inyn hert van al onledicheiden eñ inghetughen hÿlerticken dynghen so dat niet hyderlyx en blyelt tuschen gade en inyre siellen" (overal het y-teeken, mitar zonder puntjes of verticale streepjes er boven). - Verg. De Katholiek, Dl. CXXX, blz. 196 volg. 
uwen arbeit ende nader volcoemenheit altoes pynt, dat sal u voer volcoemenheit gherekent werden, als sante Bernaert seget. Voert suldi in allen uwen werken altoes ${ }^{83}$ ) merken dat oetmoedighe heilighe leven uwes brudegums ons [heren ${ }^{84}$ )] Ihesu cristi ${ }^{85}$ ) ende [u] daer nae schicken nae alle uwen vermoegen; want in sinen heiligen leven moegdi vinden een exempler ende een spiegel alre heilicheit. Ghi [sult] $\mathfrak{a}$ minlicke gheren tot synre passiën ende tot sinen liden, dat hi ${ }^{86}$ ) voer $\mathrm{u}$ gheleden hevet, ende dat altoes in uwen herten dragen ende $u$ liden daer toe trecken. Ghi en sult niet // alleen an merken synne 46r passie van buten, die hi om uwen wille gȟeleden heret; mer ghi sult in syn binnenste ghaen ende merken, wie dat hi is die om uwen wille gheleden hevet, ende sien dat hi is gheweldich got in hemel ende in eerden. Oec suldi aen merken, wt wat groeter mynnen dat hi gheleden hevet ende woe groet medeliden hi mit ons ghehadt hevet Alsoe dat hi overmits mynne ende medeliden mensche om onsen wille gheworden is Ende den bitteren doet gheleden om ons te verloessen van $\left[\right.$ der $\left.\left.{ }^{37}\right)\right]$ ewiger doeet ${ }^{88}$ ) ende ons erfgrenam te maken syns ewigen rikes ${ }^{89}$ ). Dit ende deser ghelick suldi an dencken, op dat ghi moeget verwecket ${ }^{90}$ ) werden tot synre mynnen; want, als sunte Augustyn ${ }^{91}$ ) seget, got, die van mynnen om // ons 46 v $\mathrm{g}\left[(\mathrm{h})\right.$ est]orren is, den en moegen $\left.{ }^{92}\right)$ wi [niet] bet loeven noch dancken dancken dancken [dan] myt mynnen $\left.{ }^{*}{ }^{93}\right)$. Susteren van iherusalem! wes $u$ hier an gebrect ende ghi niet vervullen en cont, dat sulldi ${ }^{94}$ ) mit oetmoedicheit ${ }^{95}$ ).... Ende pinen $u$ seer te mynnen uwen mynlicken brudegum; want my[n]ne vermach al dinc. Hier om pynt $u$ altoes op te setten in uwer herten, al ist dat ghi $u$ nact ende arme vindet van doechden, dat ghi u beteren wilt Ende hapet op die guetheit uwes ghemynden, "jole hi en sal u niet laeten; want hi is ghetrouwe, als die prophete spreket: "Die her is ghetrouwe in al sinen woerden ende heilich in alle sinen werken" ${ }^{96}$ ).

( H Hier om, o doechteren ende susteren van iherusalem ${ }^{97}$ ), gaet wt /| ende siet den warachtigen salamon onsen lieven her $47 r$ Ihesum cristum uwen brudegum, die levet ende regniert a) mit gade den vader in enicheit des heiligen geestes, got in ewicheit der ewicheit. Amen.

(Wordt vervolgd).

a) „Regnieren" (= regneren), heerschen, regeeren.

IV. 


\section{AANTEEKENINGEN.}

In deze Bijlage zijn de volgende titels aldus verkort:

Mande, Stat. = Hendrik Mande's Boecskijn van drien Staten. Het achtergevoegde getal duidt de bladzijde aan in het Eerste Deel van W. Moll, Johannes Brugman en het godsdienstig leven onzer vaderen in de vijftiende eeuw (2 din.; Amst. 1854).

Stemm. = F. H. G. van Iterson, Stemmen uit den Voortijd, Leid. 1857.

Van Helten, Spraakk. = W. L. van Helten, Middelnederlandsche Spraakkunst, Gron. 1887.

Stoett, Synt. = F. A. Stoett, Belenopte Middelnederlandsche Spraakkunst, Syntaxis ('s-Gravenh. 1889).

Stoett, Etym. = F. A. Stoett, Beknopte Middelnederlandsche Spraakkunst, Etymologie ('s-Gravenh. 1890).

$M n l . W d b .=E$. Verwijs en J. Verdam, Middelnederlandsch Woordenboek, 's-Gravenh. 1885 volg. (nog onvoltooid; DI. VI is in bewerking).

De ${ }_{n}$ Devote epistelen" worden aangehaald : Dev. epist.

1) De woorden "ihesus cristus" zijn met rooden inkt onderstreept.

2) Hoogl. III : 11 ( Egredimini et videte filiae Sion regern Salont nem", cet).

3) Na "hulpen" is een woord weggevallen: of "gades" (zie bl. 4ir: mitter hulppen gades) of gods" [aldaar, in denzelfden volzin: mitter hulpen ons mynlicken heren (met een doorgehaald "gods" na ${ }_{n}$ hulpen")].

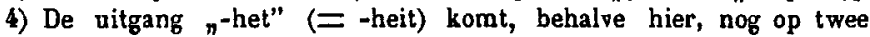
plaatsen in de Dev. epist. voor: bl. 39o (satichet) en 52r (waerhet). Ik heb de ${ }^{\mathrm{i}}$ " tusschen vierkante haakjes laten drukken, ook omdat elders meermalen deze klinker is bijgeschreven.

5) De ${ }^{i "}$ is bijgeschreven.

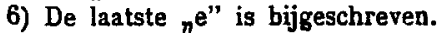

7) Duidelijkheidshalve ingevoegd.

8) De $n^{\prime \prime}$ is bijgeschreven. 
9) Met rooden inkt onderstreept.

10) Hoz. II : 11.

11) Ps. XLVI : 8.

12) Hs.: oghen. Lees : "ohren", "oren" (Mande, Stat. 290) of "oeren" (de gewone spelling in de Dev. epist.). Verg. aant. 13.

13) Ps. XI.IV : 11 ( Audi filia, et vide, et inclina aurem tuam", cet.). Voor hetgeen volgt ("Ende ist - din got") verg. vs. 12.

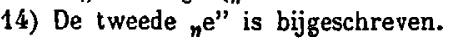

15) $H_{s .}$ : hoert hoert.

16) Met rooden inkt onderstreept.

17) Ps. XVIII : 6 (nersultavit ut gigas ad currendam viam”).

18) Spreuk. VIII : 31

19) Verg. Luc. IX : 62.

20) Philipp. IV : 13

21) Bijgeschreven.

22) Wegens eene inktvick op het midden van het woord is "lic" in margine bijgeschreven.

23) Bïgeschreven.

24) Joh. VI : 38, V : 30 , en verwante plaatsen.

25) Toespeling op het "Jerusalem caelestem" uit Hebr. XII : 22. Verg. Gal. IV : 26 ; Openb. III : 12.

26) Hs. : besiet.

27) Matth. XIX : 29 (en parallele plaatsen) in verband met Luc. $\mathrm{XIV}: 33$.

28) In margine bijgeschreven.

29) Allen $=$ alleen.

30) Hs. : dit. Lees: "dat" (zie Stoett, Synt., $\S 169$ ) of "den".

31) Hs.: ende.

32) Lefsten $=$ liefsten. Verg. bl. $64^{n}$ : onsen leven (= lieven) heren.

33) De ${ }^{\mathrm{i}}$ " is bijgeschreven.

34) Mande, Stat. 278 : verhoirt. Verg. aant. 35.

35) Ps. $X: 17$ ( Desiderium pauperum exaudivit Dominus: praeparationem cordis eorum audivit auris tua").

36) Met rooden inkt onderstreept.

37) Mande, Stat. 279 : behoudelic.

38) Mande, Stat. 279 : horen.

39) Jez. XXX:15 (nin silentio et in spe erit fortitudo vestra").

40) Spreuk. XXI : 9 of de gelijkluidende plaats XXV:24 (n Melius est sedere").

41) Heeffen, d. i. heeffe ( $=$ helfe) hem.

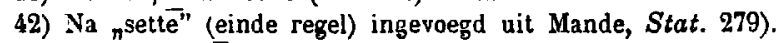

43) $H_{s}$.: on wete- (met een afbrekingsteeken); Mande, Stat. 279: onwete [term der devoten; verklaard in het Mnl. Wdb.: de toestand waarin men niets veet of gevoelt van de aarde en het aardsche (?)].

44) Ps. LXXXIV : 9

45) $H s$. : werigen.

46) Hs. : miet.

47) Hs. : Omanierlike. 
48) Verg. Hs. Colacien van Claus van Euskerken, bl. 55", 67r [H. C. Rogge en F. Pijper, Nederlandsch Archief voor kerkgeschiedenis, Nieuwe Serie, DI. III (s-Gravenh. 1905), blz. 358, 365].

49) De tweede ${ }_{n}{ }^{\text {" }}$ is bijgeschreven.

50) Verg. Matth. XXVI:39, 42 (en parallele plaatsen).

51) Hs.: ydeldelheit *

52) Met rooden inkt onderstreept.

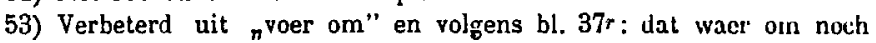
dat einde. Mande, Stat. 280: wairomme.

54) $A_{s}$ : $:$ Eñ wilt ordelen nade (einde regel) na anschync van buten. Lees: "Ende en wilt ordelen naden anschyne van buten" of "En wilt ordelen naden anschyne van buten". - Mande, Stat. 280 : en wilt niet ordelen van den aenschine van buten.

Het citaat is ontleend aan Joh. VII : 24.

55) Verg. Ps. VII : 10 en verwante plaatsen.

56) $\mathrm{Hs.}$ : dan.

57) Ingevoegd uit bl. $36^{r}$ : alle den ghenen daer ghi bi sit.

58) Mande, Stat. 280: So moghen wy vrede houden in ons ende in anderen menschen. - Verg. voor den geheelen volzin 0. A. Spitzen, Thomas à Kempis als schrijver der Navolging van Christus gehundhaafd, Utr. 1880, blz. 151.

59) Bs.: ontsenten. Doch vers. G. Visser, Hendrilk Mande. Bijdrage tot de kennis der Noord-Nederlandsche mystiek, Bijlage III, blz. 47: ${ }_{n}$ wi worden te hands ontsaet (deelw. bijv. naamw. van nontsaten") ende ontvreedt".

b0) Ingevoegd volgens Mande, Stat. 280.

61) Verg. Ruusb. (J. David, Werken, Dl. VI, blz. 173) ${ }_{n}$ Leven sunder eyghenscap enichs verkiesens" (zonder zinnelijke beyeerten). Zie $\mathbf{M I n l}$. $W d b$. op eigen sca p, $\mathrm{n}^{0} .2$.

62) Deze volzin luidt bij Mande, Stat. 281: Wy sullen alle doechden minnen in allen menschen ende die in hem loven.

63) $B$ s. : offereren.

64) $H s$. : na (met eene inktvlek er op) nae.

65) $B$ s.: : selueue.

66) Mande, Stat. 291 en Stemm. 49 : cleynheyt.

67) Ingevoegd uit Mande, Stat. 292 en Stemm. 49.

68) $B$ s.: be- (einde regel) beginne.

69) Uande, Stat. 292 en Stemm. 49: mit ghelater herten.

70) De herhaling van dezen volzin aan het begin van het volgende blad is door mij weggelaten. Wij vinden daar: Ghi sult alsoe holden dat ghi godes numer en gemisse in uwer sielen eñ dat al menschen van $\nabla$ gebetert werden die sien hoeren spreken.

71) Verg. Joh. XVIII : 36 ; ook XVII : 14, 16.

72) $H s$. : vol (einde regel) wolcoemeste.

73) Doch verg. Van Helten, Spraakk., blz. 200); Stoett, Etym., §58, $n^{0}$. 6. - In een ander gedeelte van het hs., op den zesden regel van bl. $74 r$, staat, eveneens met syncupe van ${ }{ }^{\prime \prime}$ vóór ${ }_{n} \mathrm{~s}^{\prime \prime}$, duidelijk ${ }^{2}$ gehoesamheit". 
74) Mande, Stat. 292 en Stemm. 50: naerre.

75) Waarschijnlijk valt hier niet aan eene verschrijving te denken: de herhaling zal m.j. met opzet zijn geschied en wijst op een gewoon iets, reeds in de ascetische geschriften der Middeleeu wen. Ik heb daarom de lezing nlangen langen" behouden, evenals later $n$ dancken dancken dancken" (bl. 460), "menschen menschen menschen" (480), "drucke drucke" $(57 \circ)$, nvan binnen van binnen" (610), nvoldoen voldoen" (65r) en $n^{\text {voer }}$ onse sunden voer onse sunden" (650). Verg. ons „de wijde wijde wereld" en, om een voorbeeld uit de dichters aan te halen: "Die blikt soms lange, lange.... En 't wordt hem bange, bange" (in $\mathrm{K}$ o m e $\mathrm{n}$ e $\mathrm{n}$ g a a $\mathbf{n}$ van P. A. de Génestet). - Herhalingen als nhoert hoert" (bl. 35r), nop dat dat" (45r), nguetdertieren (zoo staat er; einde regel en einde bl. 64r) guedertieren" en dergelijke houd ik voor verschrijvingen.

76) Niet onmogelijk, dat met Mande, Stat. 292 en Stemm. 50 moet gelezen worden : versmaet. Zulks past veel beter in het zinsverband en is bovendien in volkomen overeenstemming met het spraakgebruik der devoten. Verg. W. Moll, Joh. Brugman, Dl. II, blz. 423 volg.

77) "Noh" (één regel verder weder het gewone noch") behoeft geen schrijfout te wezen, vooral niet in een tekst als den onzen, die onder Duitschen invloed staat. Nog op éne plaats in de Det. epist. hebben wij een analoog voorbeeld, nl. bl. 570: rehten (= rechten), terwijl elders in het hs. (69r) als derde voorbeeld kan vergeleken worden „licht alre lihtten" (van Maria gezegd), indien althans hier niet aan eene verschrijving valt te denken. Aan Prof. Verdam dank ik de mededeeling dat de spelling ${ }^{h}$ " voor "ch" (in het Middelhoogduitsch is zij regel) niet ongewoon is in de Rein.-fragm., d.i. in E. Martin, Neue Fragmente des Gedichtes Van den Vos Reinaerde und das Bruchstück Fan Bere Wisselauzo, Strassb.-Lond. 1889 (No. 65 der Quellen und Forschungen zur Sprach- und Culturgeschichte der Germanischen Völker); wij lezen daar o. a. op blz. 5 de volgende woorden: rehte (vs. 2689), cnehte (2690), mohte (2707), dohte (2708).

78) $\boldsymbol{H}_{\text {s. : }} \mathrm{d}$ at (met eene ruimte tusschen de eerste en laatste twee letters).

79) $B$ s. : ende (einde regel en blad) ē.

80) $H$ s. : op dat dat.

81) Ingeroegd uit bl. 43 r.

82) Hs.: wercrieuen. Lees : ${ }^{\text {vercrigen" }}$ of ${ }_{n}$ vercrighen".

83) Hs. : altoes $m$ (einde regel).

84) "Heren", nlieven heren" of iets dergelijks mag niet ontbreken.

85) De woorden "Ihesu cristi" zijn met rooden inkt onderstreept.

86) In margine bijgeschreven.

87) Ingevoegd uit bl. 58 en 510 [hier: vander (in één woord)].

88) Verg. bl. 52' : bloeet; $61 \mathrm{r}$ : oeer. - In het bl. 51, voorkomende "dooet" zal wel eene fout schuilen; daar zal gelezen moeten worden "doot" of "doet".

89) Verg. 1 Petr. III : 22 ( $n$ deglutiens mortem ut vitae aeternae heredes efficeremur") 
90) De ${ }_{n} r^{\prime \prime}$ is bijgeschreven.

91) Met rooden inkt onderstreept.

92) Hs. : moegem.

93) Mande, Stat. 281 volg.: God, die van minnen om ons ghestorven is, dien en moghen wy niet bet wederlonen noch bet dancken dan mit minnen.

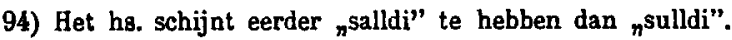

95) $\mathrm{Na}$ netmoedicheit" (einde regel) is een werkwoord of een regel weggevallen.

96) Ps. CXIIV : 13

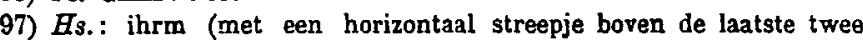
letters). Elders in de Dev. epist. altijd op de gewone wijze afgekort ihrlm (met een horizontaal streepje door de voorlaatste letter).

\section{NASCHRIFT.}

Onder het corrigeeren van dit vel (einde September 1906) heb ik gemeend hier nog te moeten doen opnemen deze twee aanteekeningen, behoorende bij blz. 317:

1) Zie over het Ursulinenklooster Jeruzalem te Venray: Het klooster "Jeruzalem" te Venray (in De Maasgouro, DI. VII, blz. 93 volg.); J. A. de Rijk, Het Ursulinen-klooster en Pensionnaat Jerusalem te Venroy in den Volkes-Almanak voor Nederlandsche Katholieken (Jaarg. 1891, blz. 63 volg.; Jaarg. 1892, blz. 233 volg.; Jaarg. 1893, blz. 195 volg.; Jaarg. 1894, blz. 85 volg.)]. Met eene afbeelding van het klooster in 1884. - Verg. J. G. R. Acquoy en H. C. Rogge, Archief voor Nederlandsche kerkgeschiedenis, DI. IV ('s-Gravenh. 1893), blz. 405.

2) De „Uitspraken van „leismeysteren" en „Exempelen aangaande hen" zijn reeds in druk verschenen, en onder den titel "Uitspraken en Exempelen" opgenomen in De Ratholiek, Dl. cxxx (jaarg. 1906, II), blz. 185-198.

D. A. B. 